mansasa

glyndŵn

Glyndŵr University

Glyndŵr University Research Online

Social Inclusion Research Unit

Social and Community

$1-1-2010$

\title{
Women's Safety Service within the Integrated Domestic Abuse Programme: Perceptions of Service Users
}

Iolo Madoc-Jones

Glyndwr University, i.m.jones@glyndwr.ac.uk

Karen Roscoe

Glyndwr University, k.roscoe@glyndwr.ac.uk

Follow this and additional works at: http://epubs.glyndwr.ac.uk/siru

Part of the Criminal Law Commons, Marriage and Family Therapy and Counseling Commons, and the Social Work Commons

(C) 2010 Blackwell Publishing Ltd This is the pre-peer reviewed version of the following article:

Madoc-Jones, I. \& Roscoe, K. (2010) 'Women’s Safety Service within the Integrated Domestic Abuse Programme: Perceptions of Service Users'. Children and Family Social Work, 15(2), 155-164. This article was originally published in the Journal of Children and Family Social Work in 2010, by Blackwell Publishing. The definitive version is available at http://www3.interscience.wiley.com

\section{Recommended Citation}

Madoc-Jones, I. and Roscoe, K. (2010) ‘Women’s Safety Service within the Integrated Domestic Abuse Programme: Perceptions of Service Users'. Children and Family Social Work, 15(2), 155-164

This Article is brought to you for free and open access by the Social and Community at Glyndŵr University Research Online. It has been accepted for inclusion in Social Inclusion Research Unit by an authorized administrator of Glyndŵr University Research Online. For more information, please 
Women's Safety Service within the Integrated Domestic Abuse Programme:

Perceptions of Service Users

Iolo Madoc-Jones and Karen Roscoe

\title{
Women's safety service within the Integrated Domestic Abuse Programme: perceptions of service users
}

\begin{abstract}
This paper draws on the findings of a qualitative evaluation that examines women's perceptions of the services provided to them whilst the men who have abused them attended an Integrated Domestic Violence Programme in one Probation area in the UK. Research focusing on domestic violence programmes has mostly concentrated on the experiences of male perpetrators. As a result, less is known about how women feel about such programmes and the parallel safety services they are supposed to receive. This research seeks to address that weakness by exploring the perceptions of thirteen women whose violent and abusive partners/ex-partners are attending one perpetrators programme. The findings of our study suggest that women are generally negative about perpetrators programmes and require more comprehensive and co-ordinated services than are routinely made available to them. The paper suggests that women value and need direct and assertive support as well as safety services and this need is especially pronounced in rural contexts where women can be isolated from mainstream services. The implications of the research to practice with victims of domestic violence are discussed to inform further development of IDAP and similar programmes in the U.K. and beyond
\end{abstract}




\section{Introduction}

This article presents research conducted into the service provided to victims of abusers who are attending a groupwork domestic violence programme in one Probation Area in the U.K. Terminological sensitivities exist in the field of domestic violence and abuse. For the purposes of this article we use the terms 'women', 'victims' and 'domestic violence'. We focus on 'women' because the participants interviewed for this research were all women and we use the term 'victim' because they were all victims in terms of their status within the Criminal Justice System in which they were involved. We use the term 'domestic violence' because all the women in this research had experienced domestic violence from men with whom they were, or continued to be, in a close personal relationship. As Hague and Mullender (2006) and Fugate et al (2005) point out, the voices of women who have experienced domestic violence have rarely been heard and especially by professionals and agencies trying to provide them with a service. This article seeks to address that silence by exploring the services that are offered to women when their abusers are attending the Integrated Domestic Abuse programme (IDAP) either as part of a court mandated community order or on licence from prison in the U.K.

\section{Literature Review}


Domestic violence is a significant criminal justice and social policy issue and the scale of the problem is well documented worldwide (Hague \& Mullender, 2006; Harwin, 2006). In the U.K. it is estimated that one in four women will experience some form of domestic violence at some point in their lives (Coleman et al, 2007). It is known that such experiences can cause serious short and long term physical, emotional and psychological harm to the women and children who bare the brunt of it (Carlson, 2000; Wilke \& Vinton, 2005; Smith-Stover, 2005). In the U.K., as a result, numerous policy initiatives have sought to address the problem (Rees \& Rivett 2005, Harwin, 2006). Because domestic violence is an issue which does not fit neatly within the responsibilities of one agency or Government department, these initiatives have more recently emphasised the importance of so called 'joined up' partnership working, especially when there are children involved. Inter-agency domestic violence fora involving the police, social services, and housing agencies have therefore been set up across most counties in England and Wales. The setting up of these fora has been accompanied by a rise during the 1990's in the number of Criminal Justice based perpetrator programmes available for violent men (Seith, 2001, Dobash et al, 2000).

Since 2003 the Correctional Services Accreditation Panel has required each of the 43 Probation Areas (or latterly trusts) in England and Wales to exclusively deliver either the IDAP or the Community Domestic Violence Programme (CVDP). Currently 34 Probation areas run the IDAP and nine run the CVDP (National Probation Service, 2008). Delivery of the IDAP is subject to national standards that are outlined in a national practice manual for Probation workers (National Probation Service, 2004). The IDAP programme is run over 27 weekly sessions to groups of up to eight male perpetrators and derives its rationale from the Duluth Domestic Abuse Intervention Project in the USA (Pence \& Payman, 1990). From the 'Duluth' pro-feminist perspective, violence and intimidation are understood as the outcome of normal male socialisation and as tactics employed by men to maintain power and control over women. 
Proceeding from the perspective that the use of violence by men is legitimated by a patriarchal social system, the programme's aim is resocialisation and to help men end their violent and abusive behaviour by developing social skills, an understanding of the tactics of power and control and insight into the experiences of women.

As Mullender and Burton (2001) point out, interventions with domestic violence perpetrators are fraught with difficulties. This is because there is a danger that unless the work is well thought through it will either fail to address the real needs of violent men or place some women in greater danger. Accordingly, the IDAP practice manual highlights that a Women's Safety Service, delivered either by Probation staff or a partner agency, must accompany the IDAP. The IDAP manual states that the main roles of the Woman's Safety Worker are gathering information on the male perpetrator and personal safety planning. Information is sought from women about men's behaviour to inform the supervision process and to orientate role plays and discussion within the IDAP towards salient themes and issues. Safety planning is undertaken with the specific aim of helping women and, if relevant, their children stay safe. Information gathering and safety planning begins at an initial meeting before a man attends the IDAP. At this meeting the Women's Safety Worker guides the woman in preparing a safety plan with details of what actions might be taken, and who the woman might contact (in addition to the police) should further abuse occur. The importance of a safety focus has been highlighted in research by Hester et al (2006). They found that $50 \%$ of a sample of 356 men convicted of domestic violence reoffended within three years and that $80 \%$ of these incidents were against the same partner. Research has suggested that abuse may not end even when a woman with children leaves an abuser. Women who have recently left their partners for example are at greatest risk of being killed (Wilson \& Daly 1993). Offering a Safety Service to women who have decided to leave their abusive partner is therefore equally as important as offering a service to women who have decided to stay with their abusive partner (Shalansky et al, 1999). A focus on 
safety, especially within the home, can help women and children hold on to some normality in their lives and avoid the need for them to leave their homes and communities and enter shelters in order to be safe (Erez \& Ibarra, 2007).

The IDAP manual states that after an initial meeting, the Women's Safety Worker is expected to undertake three further meetings with the woman at the mid-point and end of the IDAP, and then six months later. The main purpose of these additional meetings is to continue to receive information from women for assessment and evaluation purposes of men on the IDAP. Equally they provide an opportunity to review and if necessary to update personal safety plans. Information about mens progress on the IDAP may also be given to women at these meetings. This is so that attendance on the programme is not used to abuse women further. Ways in which attendance might be abused include falsely reporting back that programme staff believe women are responsible for provoking men into violence, or suggesting that attendance on the programme will cure men and make them safe to be with (Mullender \& Burton, 2001). Although the service may be experienced by women as supportive, providing support is not a role of the Women's Safety Worker. If a woman requires support services then the role of the worker is to give women information about where they might go to obtain that service.

Research on the effectiveness of perpetrators programmes in terms of preventing reoffending report, at best, modest effects on recidivism (Bennett et al 2007, Bowen et al 2002) Less research has been conducted into the experience of the victims of men attending such programmes. Whilst it is possible that methodological problems give rise to this situation in that victims may have been hard to access, afraid or unwilling to participate in research, Herman (2005) suggests that as likely is that the views of victims have not been valued within the Criminal Justice System. The post-modern turn however has underpinned a growing interest in diverse forms of knowing and thereby in the knowledge of service users in a range of contexts 
(Mullender \& Hague 2005; Erez \& Ibarra, 2007). In particular in the criminal justice contexts this has given rise to attempts to explore the role victims' knowledge might play in rehabilitative and restorative justice purposes.

Pre-dating the development of the IDAP, Burton et al (1998) found women were positive about the support and safety service they received from the Hammersmith Domestic Violence Intervention Project. In evaluating two of the first ever domestic violence prevention programmes in the UK on the other hand, Dobash et al (2000) found that lack of funding hindered the introduction of specific services for women and this prompted them to wonder...

to what extent can the theoretical orientation of the programme be directed primarily towards the safety and protection of women as opposed to the personal and psychological development of men?

A year later Mullender \& Burton (2001) found that out of nineteen perpetrators programmes running at the time, three did not seek to keep women informed of the progress of men on the programme. The authors also found that overall the practice in relation to working with victims was inconsistent. To date, there has only been one research project commissioned by the Home Office specifically on the IDAP. This research focussed on the early stages of the development and implementation of IDAP and not on rates of recidivism or the views of victims (Bilby \& Hatcher 2004). A study of the supervision of community orders in the Probation Service in 2006 however reported that many Probation Areas have been unable to meet the demand for the IDAP (National Audit Office, 2006). More recently a Government select committee received evidence that women whose abusers were referred on to the IDAP faced delays in receiving safety services. This was typically because no service was available until the male perpetrator 
had begun the programme and there were often delays in that regard (House of Commons: Home Affairs Committee, 2008).

Outside the criminal justice system there is evidence of wide variations in the provision and quality of services on offer to victims of domestic violence across the country (Home Office, 2005). According to Coy et al (2008) one third of local authorities in England and Wales have no specialized support services for women who experience domestic violence. Many of the services that do exist are assessed as being underfunded or otherwise under resourced. As Grama (2000) points out, in some rural settings services may be especially poorly developed. Addressing basic safety issues may be very difficult for example if there is no local police station. Burman et al (2004) identify that services for minority groups are very poorly developed even in major U.K. cities characterized by considerable ethnic diversity.

As Davis (2002) points out, women who experience domestic violence often show remarkable inner courage and resilience in their lives. But as Fugate et al (2005) identify, some women may be reluctant to approach services for help. Various practical barriers such as having no money or time can make accessing services difficult for some women. For others, fear of being blamed for their situation may prevent them asking for help. Some research suggests that some women want service providers to be more proactive in coming forward to offer services to them (Greenan, 2004, Fitzpatrick et al, 2003). For example Parker et al (1999) found that in a hospital setting, attending a nurse delivered empowerment session focusing on safety was valued more by victims of domestic violence than being given a card with resource phone numbers. 
Since the 1990's Probation areas have been required by successive Governments to establish formal partnership relations with voluntary agencies (Gibbs, 2001). This has led to the introduction of a contract culture around Probation practice. Women's Safety Services linked to IDAP have therefore been contracted out to non-profit women focussed agencies in some areas across England and Wales. Gibbs (2001) and Walklate (2008) highlight challenges and dangers that can arise in the process of joint working in partnerships. This includes either a agency losing its own identity and being co-opted to meet the needs of the stronger partner, or agencies ending up in overt or covert conflicts.

\section{The Service}

The organisation delivering the Women's Safety Service is a charitable Housing Association that was first established in 1989. Though initially it operated under the Women's Aid umbrella and provided supported housing for women leaving refuges, more recently it has developed as an independent agency to offer floating support services to vulnerable women and children in their own homes. Forty three projects provide services to an average of 700 women and 1050 children and young people in eighteen Local Authority areas. Staff are trained to offer housing, employment and welfare rights advice as well as 'listening ear' type counselling services. The association maintains close links with other agencies that accept referrals to address drug, alcohol, legal or mental health needs. The overall aim of the organisation is to help service users live independently. Since 2006 the agency has employed two part time staff to undertake a Women's Safety Service across one Probation Area. At any one time these workers provide a service to around 90 women and their children.

\section{Methods}

As Langford (2000) argues 
Qualitative research involving battered women requires advanced planning to protect participants and the investigator from the risk of violence from an abusive partner (p.133)

Accordingly this research was planned with safety in mind and comprised semi-structured faceto-face or phone interviews with service users of the Women's Safety Service. Between May and July 2008 all women who had engaged with the Women's Safety Service (except those who were identified as being in too much distress) were contacted by the Women's Safety Workers about the research. The Safety Workers used protocols for doing this that they had agreed with the women in the past. The women were either given verbal or written information about the research and the opportunity to opt into the project, and be interviewed at a neutral venue near where they lived, or by phone, by either a male of female researcher. In total, thirteen women participated in the study- two opting for a face to face interview, eleven for telephone contact. When a phone call was chosen, women identified the day and time when it was convenient for that call to take place. Before phoning, the researchers agreed that if the phone were to be answered by a male, they would ask to speak to a person not living at the address. It was agreed no messages would be left on answering machines. Participants signed a consent form or gave verbal consent to engaging in the project. Because violent men often go through their partner's belongings (Langford 2000) those signing forms or taking information leaflets were given the option of leaving them behind if they so wished. Expenses to attend interviews were paid and the interviews were tape recorded with the respondent's permission and then transcribed. Women were assured that what they said would be kept confidential unless issues arose which made the researchers believe that they or their children were in imminent danger. In this case, women were told that the researcher would have to pass on their concerns to the Women's Safety Workers. Interviews with the women focussed on reasons for take-up of the 
service, previous participation in programmes, access and waiting, service experiences and outcomes, perceived advantages and disadvantages, and future recommendations. In addition, the two staff responsible for delivering the Women's Safety Service and their manager were interviewed. They also signed consent forms and were given the same assurances as the women service users. Interviews with the staff focussed on the challenges and issues they perceived as relevant in delivering a safety service to women.

Data analysis was informed by the principles of grounded theory and used a constant comparative approach. This involved identifying key themes from interview transcriptions and other relevant research material. Extracts from the data set are presented here as evidence of identified themes. Respondent identifiers ( $r 1-r 13$ for service users, $r 14-16$ for service providers) are used to maintain confidentiality. Ethical guidelines provided by the British Sociological Association (2002) were observed, and the research was approved by Glyndwr University's Research Ethics Committee. Respondents were informed that their contributions would be anonymous and of their rights to withdraw or terminate interviews at any stage without their statutory rights or any future connection with services being affected.

\section{Findings}

\section{Importance of Support}

The women's evaluations of the services they had received from the Women's Safety Service was overwhelmingly positive. Feelings of having been abandoned by the Criminal justice System until the Women's Safety Worker contacted them were commonplace. Respondent one was still in a relationship with the man who had been violent towards her. She commented 
He had probation, his solicitor and everyone helping him with his problems but until XXX came along no-one seemed interested in me, there was no-one at all for me (r1)

A recurring theme to emerge was that whilst the women could recall having discussions with the Women's Safety Workers about safety planning, the service they were getting was understood primarily in terms of support. Indeed the Women's Safety Workers were often referred to as the "support worker". Only a few respondents could recall details of their safety plan and those that did commented that such plans were not really that helpful because they had either already discussed physical security issues with a police representative on a "bobby" scheme operating in the area- fixing locks, putting in panic alarms etc, or they were used to thinking about safety issues having experienced domestic violence for many years. Respondent Seven for example, a women who has lived with a violent partner for several years and had two children, suggested

The safety support plan (sic) didn't really make a load difference because l'd already sorted things out anyway...you know..the little un's knew to go and hide in the garden or go to to XXXX next door, (r7)

Most respondents commented however on how they valued the emotional and practical support provided by the Women's Safety Worker. Reference was most frequently made to the therapeutic value of simply talking to someone about their experiences. Many women described receiving levels of emotional and practical support well above what is expected within the Women's Safety Worker remit of the IDAP. His emotional and practical support also continued for much longer periods than required. Respondent six for example, who identified that even though her violent partner was in jail that she was still scared to leave the house, commented 
she went through the safety plan with me then she phoned me up quite regularly to make sure things were ok... she helped me talk things over and calm me down....she also helped with benefits and in getting a solicitor, she drove me to see him and stayed with me (r6)

By way of explanation for this level of service, the Women's Safety Workers perceived that what many women wanted and needed was well above what was covered by the IDAP remit. Providing direct support at times was perceived as essential and simply offering a Safety Service was perceived as inadequate.

\section{Assertive Victim Focussed Contact}

At the time of their initial contacts with police, most respondents could recall receiving information sheets about services they could contact for support. Few however reported taking up such services and the primary reasons given for this was that such services were either not needed or that women had negative experiences of such services in the past. In this context, that the Women's Safety Workers had phoned them up and 'promoted' the service on offer seems to have been influential in persuading the women to engage in the Safety Service. Respondent four for example offered:

At first I didn't want to speak to your (sic) worker, but she phoned, said she could help and she would come round and when I did ..she came round and she was kind and helpful (r4)

Whilst respondent six described the initial contact as being presented to her in such a way as to involve very little effort on her part 
XXX rang me and said she's like to come round if only for a quick chat and I thought well..ok, it was easier that way..she came to me (r2)

The Women Safety Workers identified that this approach to offering a service was untypical in the field of domestic violence. Women's Aid for example was identified as an agency that did not take referrals or assertively contact women until a woman had first contacted them. The Women's Safety Workers identified that only very rarely did a women turn down the offer of a face to face meeting with the Safety Worker if the worker offered to go out to see her.

\section{Empathy}

A number of respondents commented how a willingness on the part of workers to share personal experiences of domestic abuse made trusting the worker and talking to them easier. Shame and guilt were commonly expressed by the women. Because they disclosed personal experiences of abuse, the Safety Workers seemed able to present themselves and what they had to say in a non-judgemental way. Respondent four for example, who had been to other agencies for help and support commented

The service was a real surprise... I needed to tell somebody and somebody who didn't know me... but in a way it was like we'd been friends for years, she understood me and I could tell them everything not parts or pieces, you could be totally open and honest... (r4)

Respondent eight had also approached agencies for help in the past. In identifying what was different about the current service she commented: 
I don't know...XXX doesn't come across as very stern, doesn't come across all "you must do this and you mustn't do that" ( $r 8)$

The Safety Workers themselves described their approach to their work as being empathic and empowering. They described how they would avoid 'lecturing' the women they saw and how they focussed on building the women's self confidence. Despite the Women's Safety Service being provided by an organisation allied to the Women's Aid movement, a number of respondents compared alternative services unfavourably with the services they were currently receiving. The comments made by respondents eight and six suggested that the problem for them may have been that at times some agencies had too assertively promoted a particular a rationale for domestic violence:

Here its been good..but I don't know with Women's Aid they're more in your face and l'm not good with that (r6)

We started asking for help before it escalated to the degree it did..we went to alcohol services and relate..when we started telling our story she said "you're the one with the problem... there's nothing wrong with him going for a pint ( $r 7)$

\section{An Adversarial Stance to the Criminal Justice System}


Whilst the women understood that the Women's Safety Services was offered to them because their abusers were attending the IDAP, this understanding existed alongside a perception however that the service was not allied to the Police or Probation Service. Hence the women were able to articulate an adversarial relationship with these latter agencies, but a positive relationship with the Women's Safety Service. Despite the Women's Safety Service being commissioned by the Probation Area respondent two, for instance offered that:

Probation never did nothing for him or me.. didn't even talk to me... if it wasn't for XXXX I wouldn't know a thing about what's going on with him (r2)

The Women Safety Workers understood that this adversarial stance arose partly because the women perceived that offenders who had been given community orders had been 'let off' and primary responsibility for this was seen to lie with criminal justice staff. Associated with this, the women respondents were pessimistic about the prospects of the IDAP having any effect on their abusers, and worried that Probation staff were susceptible to believing everything offenders would tell them. Respondent eight expressed her dissatisfaction with Probation by referring to a power imbalance which she felt was unfair when her partner had to see his Probation Officer

If he needed to change an appointment it was inconvenient, but if they wanted to change at the last minute it was alright, they seemed to think because he was the offender he was expected to fall into line and I told them straight "don't expect him to respond to you just dictating to him like that" (r8) 
At times the women sought to co-opt the Women's Safety Workers into an adversarial relationship with other criminal justice agencies. At these times the relationship between the Women's Safety Workers and the women was presented as one of "us against them" and the insight that the women and their 'support workers' had was frequently contrasted with the lack of insight criminal justice staff had.

\section{The Challenges of Rurality}

Because they lived in rural settings and had no means of transport, many women identified that the Safety Workers were often the only sources of support available to them. The safety workers themselves identified that in such instances signposting women to additional 'support' services was often not an option. This caused some tension for the Safety Workers- whilst they were aware that their role was to address safety issues, they were also aware that little alternative support was available to some of the women. Respondent nine for example lived in a small market town outside of the main conurbations in the area and identified that she did not

drive. In reporting experiences of going for help in the past she expressed difficulties due to being isolated but also, at the same time, visible in her community,

It's pretty quiet round here so there's nothing here... its good it's quiet but everyone knows everything about you, they're into your business, (r9)

\section{Working Relationships}

Many respondents identified good liaison between the Women's Safety Service and the IDAP 
He was using the IDAP to get at me..coming home and saying I know what you're doing to try to wind me up..he's quite clever in using the IDAP in a different way....but that's the kind of information XXXX will feedback to the IDAP (r4)

Despite this, not all respondents understood that lines of communication were open between Women's Safety Workers, Probation Officers and staff delivering the IDAP. Respondent five for example commented

R5 We went to Spain earlier in the year and he behaved appallingly

Q What did the XXX do with that information (r5)

R5 I don't know...maybe that's not her place to go back to the probation service and tell them (r5)

Whilst respondent eight in response to a question about what the Safety Worker did with information given to her responded "I assume it was confidential" (r8)

Equally at times basic information did not seem to have been conveyed to the women. Respondent twelve for example gave the following account of seeing her abuser:

...I was out shopping and I saw him in town once when I thought he was still in prison and that was a shock..i phoned up xxx and she got in touch with probation who said he's been let out about a month before (r12) 
Most respondents indicated they were not routinely kept informed of a man's progress on the IDAP. Equally most felt they felt they were not able to influence the course of the programme or its content through giving feedback.

Such accounts need to be understood alongside comments made by workers that difficulties arose for them as staff external to the Probation Service in having access to service records and regular contact with Probation staff who were spread across a large geographical area. Women's Safety Workers reported having problems negotiating the complexities of keeping several lines of communication open- between an offender's supervising Probation Officer, the IDAP staff, members of the police public protection unit (PPU)and themselves ;

There's a problem making sure everyone knows what they need to know. That's from both directions. I think if we could access the probation database we'd have a much better sense of what's going on and it would be much easier to liaise with staff about what we know. You can tell the programme team something but find that the probation officer didn't know and then no-one knows who's responsibility it is to tell the PPU (r15)

\section{Insight}

A final theme to emerge relates to the type of insight shown by women into their experiences. Not one respondent conceptualised the violence they had faced with reference to the underlying 'gender power' philosophy of the IDAP programme or the Women's Safety Service, or made reference to such concepts as power, control or patriarchy. Almost all the women, to varying degrees, understood the men's use of violence with reference to alcohol, early childhood abuse or the woman's own behaviour as the following extracts demonstrate 
He grew up in an environment, his family were all ex-army, a lot of the problems that he had was with expressing himself in...he's triggered in a different way from other people $(r 7)$

He's more laid back now, he doesn't drink and I don't let him drink, he's a different person when he's sober ( $r 1)$

A few of the women from one locality reported having attended a groupwork programme for victims of domestic violence run by the same agency as provided the Safety work. Despite this, almost all the women continued to express sentiments that they were equally culpable for the violence they had experienced. They struggled to understand and express a perspective on domestic violence that might be more empowering.

\section{Discussion and Practice Implications}

This research gives raise to a number of practice implications associated with the provision of services to women when their abusers are on the IDAP or other similar domestic violence perpetrators programme.

The first practice implication is that sometimes it may be appropriate to combine a support and safety role. This is because the conceptualisation of safety and support as two distinct areas in working with victims of domestic violence may be problematic. Whilst the women in this study were entitled to a Safety Service, what they overwhelmingly wanted, valued and seemed to benefit from was a support service. The supportive relationship that the women had with the Women's Safety Workers however was clearly the context wherein safety issues were also 
discussed. Safety and support therefore went together. Support engendered trust which in turn allowed for the free flow of information to address ongoing issues of abuse and keeping the women, and in some cases their children, safe.

In addition to this the research suggests that as Grama (2000) and Coy et al (2008) have already indicated, the strategy of signposting women to additional support services remains problematic. For some women in this research accessing additional support services was not an option because services did not exist or they were isolated from services by rurality. However the problems with a signposting strategy go beyond problems of access. Whilst isolation was understood as a major barrier to accessing service, it was not the case that those women who had cars and could drive accessed additional support services to a greater degree than other women. Whilst many women claimed that they did not access other support services because they did not need them, these same women took up and valued additional support provided by the Women's Safety Workers and, over time, turned to them for advice, guidance and emotional support. This may be because, as Greenan (2004) and FitzpatricK et al (2003) have suggested, domestic violence perpetrators attempt to dominate, isolate and control women, and so whilst many women need help to recover from such experiences, many will feel shame and a lack of confidence in approaching support services. As a result signposting women to support services is likely to prove an ineffectual strategy to providing services to many women who have experienced domestic violence.

A second practice implication from the research relates to who should provide Women's Safety Services. As Walklate (2008) identifies, women are usually reluctant to approach officialdom to address issues of domestic violence. Many of the women in the current research positioned themselves in an adversarial relationship with agencies of the Criminal Justice System and were negatively orientated towards the Police and Probation. Whilst the women in this research were 
not always well disposed to Women's Aid type services either, Women's Safety Workers allied to agencies whose primarily purpose is providing support services for women presented as better positioned to successfully engage with women on support and safety issues. Especially relevant may be the ability of Women's Safety Workers in such agencies to provide ongoing support and safety services to Women even after their involvement with the IDAP programme has come to an end. Like the Women Safety Workers in the current research, such workers may be able to provide ongoing support and safety services as part of their agencies mainstream supportive functions after the IDAP has finished. At the end of the IDAP therefore women are not left on her own to cope whilst the Probation Service tiptoe quietly out of the door having signposted the woman to additional services.

The first two practice implications give rise to the third and fourth practice implications that when provided, both safety and support services should be adequately funded and guided by clear protocols for practice. In the current research, the Safety Workers often found themselves in the impossible position of either having to leave women without sources of support, or provide it themselves. More often than not the safety workers dealt with this dilemma by providing support themselves. Overwhelmingly in these instances the support was valued however its provision had implications for the Safety workers and the organization providing the Safety Service that had not been fully resolved. These were in terms of the resources allocated to the work relative to the funding they received, and going beyond the strict IDAP safety remit without adequate and agreed protocols in place with the Probation Service to manage the issues that clearly did arise.

Supporting and empowering women requires levels of resourcing well above that needed to service four timetabled safety focussed appointments. At the same time providing a dual safety and support service requires protocols to be in place to manage the flow of information that 
arises when safety workers have ongoing, as opposed to timetabled contact with women. Protocols are required to formalise an understanding between the worker and the women that support is not unconditional and that absolute duties exist for the workers associated with their safety remit.

A fifth practice implication is that programmes should be developed with the aim of helping women re-author their experiences as victims of domestic violence. The women interviewed for this research did not appear to have developed a critical consciousness about the abuse they had experienced and seemed to blame themselves for the violence that had been inflicted on them. This raises concerns that an opportunity is being missed to inure women both against the long term effects and future experiences of domestic violence. The development of a critical consciousness is not part of the remit of the Women's Safety Worker and the workers in the current research did not conceive of themselves as having the time to engage in such activities. Providing resources and space for such activities however may be a necessary part of an holistic response to victims of domestic violence

A final practice implication arising from the research is that communication between staff involved with IDAP should be improved. The Women's Safety Workers identified lack of access to in-house Probation Information technology systems as a significant barrier in communicating with and receiving information from relevant Probation staff. In the current research there was evidence that as a result staff did not adequately communicate with each other and that at times this had the potential of putting women at risk. Problems with communication are likely to be more acute and to need addressing in instances where Women's Safety Services are provided by staff external to a Probation Area.

\section{Conclusions}


The research findings presented in this paper lead to the conclusion that in some circumstances it may be appropriate for a dual support and safety service to be provided to women when their abusers are attending a domestic violence perpetrators programme. Moreover that such support/safety services might be better provided by an agency outside of the Probation service with the empowerment of women as their goal. With adequate levels of resourcing and protocols in place to manage dual safety and support services, such arrangements could avoid a scenario whereby some abused women are left without adequate sources of safety and support, and some workers attempt to fill the gap without appropriate training and guidance.

Limitations to this study include the small sample size and that it is likely that only women who had more extensive contact and investment in the Safety Service and believed they had something to say would have agreed to be interviewed. Within this however, the findings were consistent within and between the service user and provider respondents and so it is possible to summarise that service users were positive and appreciative about the service on offer to them, and this may have been because the service offered went beyond considering safety to addressing some issues related to practical and emotional support.

Words: 6194

\section{Acknowledgements}

We gratefully acknowledge the participation of all service users and providers of the service who took part in the study. Also Professor Odette Parry for comments on earlier drafts of this paper. 


\section{References}

Bennet,L. Stoops,C. Call,C. \& Flett,H. (2007) Program Completion and Re-arrest in a Batterer Intervention System. Research on Social Work Practice, 17, (1), 42-54.

Bilby, C. \& Hatcher, R. (2004) Early Stages in the Development of the Integrated Domestic Abuse Programme (IDAP): Implementing the Duluth Domestic Violence Pathfinder, Home Office online Report, 29/4.

Bowen,E. Brown,L. \& Gilchrist,E. (2002) Evaluating Probation Based Offender Programmes for Domestic Violence Perpetrators: A Pro-Feminist Approach. The Howard Journal, 41,(3),221-236

British Sociological Association (2002) Statement of Ethical Practice for the British Sociological Association. British Sociological Association. Durham.

Burman,E. Smailes,L. \& Chantler, K. (2004) Culture as Barrier to Service Provision and Delivery: Domestic Violence Services for Minoritised Women. Critical Social Policy,24, (3),332357.

Burton,S. Regan,L. \& Kelly,L. (1998) Supporting Women and Challenging Men: Lessons from the Domestic Violence Intervention Project. Policy Press, Bristol.

Carlson,B.E. (2000) Violence Against Women: Synthesis of Research for Service Providers. Washington DC: National Institute of Justice Document No 199578 (Available to view at http://www.ncjrs.gov/pdffiles1/nij/grants/199578.pdf last accessed 30/7/08)

Cavanagh,K. (2003) Understanding Women's Responses to Domestic Violence. Qualitative Social Work Vol 2, no 3 pp. 229-249

Coleman, K. Jansson, K. Kaiza, P. \& Reed, E. (2007) Homicides, Firearm Offences and Intimate Violence 2005/2006. In: Supplementary Volume 1 to Crime in England and Wales 2005/2006. Home Office/Research, Development and Statistics Directorate: London 
Coy,M. Lovett,J. \& Kelly,L. (2008) Realising Rights, Fulfilling Obligations: A Template for an Integrated Strategy on Violence Against Women for the U.K. Ending Violence Against Women, London.

Davis,R.E. (2002) The Strongest Women: Exploration of the Inner Resources of Abused Women. Qualitative Health Research, 12, (9), 1248-1263.

Dobash,R. Cavanagh,K. Dobash,R. \& Lewis,R (2000) Domestic Violence Programmes: A Framework for Change. Probation Journal , 47, (18),18-29.

Erez,E \& Ibarra,P.R (2007) Making Your Home a Shelter. British Journal of Criminology, $47,100-120$.

Fitzpatrick,S. Lynch,E. Goodlad,R. \& Houghton,C. (2003) Refuges for Women, Children and Young People in Scotland: A Research Report. Scottish Executive, Edinburgh.

Fugate,M. Landis, L. Riordan, K. Naureckas,S. \& Engel,B. (2005) Barriers to Domestic Violence Help Seeking: Implications for Intervention. Violence Against Women, 11, (3), 290-310.

Gibbs, A. (2001) Partnerships Between the Probation Service and Voluntary Sector Organisations. British Journal of Social Work, 31, 15-27

Grama, J. (2000) Women Forgotten: Difficulties Faced by Rural Victims of Domestic Violence. Journal of Family Law, 14,173-189.

Greenan, L. (2004) Violence Against Women: A Literature Review. Scottish Executive, Edinburgh.

Hague, G. \& Mullender, M. (2006) Who Listens? The Voices of Domestic Violence Survivors in Service Provision in the United Kingdom, Journal of Violence Against Women ,12, 568- 587. 
Harwin,N. (2006) Putting a Stop to Domestic Violence in the United Kingdom: Challenges and Opportunities. Violence Against Women, 12, (6), 556-567.

Herman,J.L. (2005) Justice from the Victim's perspective. Violence Against Women, 11 (5) 571602.

Hester,M. Westmarland,N. Gangoli,G. Wilkinson,M. O’Kelly,.C. Kent,A. \& Diamond,A. (2006) Domestic Violence Perpetrators: Identifying Needs to Inform Early Intervention. University of Bristol and Northern Rock Foundation and Home Office: Bristol.

Home Office (2005) Domestic Violence- A National Report. Home Office, London.

House of Commons-Home Affairs Committee (2008) Domestic Violence, Forced Marriage and "Honour"-Based Violence, HC 263-I, Sixth Report of Session 2007-08 - Volume I: Report. The Stationery Office: London

Hubble, M. Duncan, B. \& Miller, S. (1999) The Heart and Soul of Change, What Works in Therapy. American Psychological Association, Washington:

Kelly, L. (1999) Domestic Violence Matters : An Evaluation of a Development Project. Home Office Research Study 193. Home Office London:.

Langford,D.R (2000) Pearls, Pith and Provocation: Developing a Safety Protocol in Qualitative Research Involving Battered Women. Qualitative Health Research, 10, (1)133-142

Mullender,A. \& Burton,S. (2001) Good Practice With Perpetrators. Probation Journal,48, 260268.

Mullender ,A. \& Hague,G. (2005) Giving a Voice to Women Survivors of Domestic Violence Through Recognition as a Service User Group. British Journal of Social Work, 35, (8)13211341. 
National Audit Office (2008) The Supervision of Community Orders in England and Wales. National Audit Office, Bristol.

National Probation Service (2004) IDAP- Practice Manual. National Probation Service, London.

National Probation Service (2008) Intervention News. 28 February 08. National Probation Service, London

Parker,B. McFarlane,J. Soeken,K. Silva,C. \& Reel, S. (1999) Testing an Intervention to Prevent Further Abuse to Pregnant Women. Research on Nursing and Health, 22,59-66.

Pence,E. \& Payman,M. (1990) Power and Control: The Tactics of Men Who Batter: an Educational Curriculum. Minnesota Programme Development, Duluth.

Rees,A. \& Rivett,M (2005) Let a Hundred Flowers bloom, Let a Hundred Schools of Thought Contend': Towards a Variety in Programmes for Perpetrators of Domestic Violence. Probation Journal, 52,(3) 277-288.

Respect (2000) Statement of Principles and Minimum Standards of Practice. Respect, London.

Seith,C. (2001) Security Matters: Domestic Violence and Public Social Services. Violence Against Women, 7, 799-820.

Shalansky,C. Ericksen,J. \& Henderson,A. (1999) Abused Women and Child Custody: The Ongoing Exposure to Abusive Ex-Partners. Journal of Advanced Nursing, 29, (2), 416-426.

Smith-Stover, C. (2005) Domestic Violence Research: What Have We Learnt and Where Do We Go From Here? Journal of Interpersonal Violence, 20, (4), 448-454.

Walklate,S. (2008) What is to be Done About Violence Against Women. British Journal of Criminology, 48, 39-54. 
Wilke,D.J. \& Vinton,L. (2005) The Nature and Impact of Domestic Violence Across Age Cohorts. Affilia, 20,(3),316-328.

Wilson,M. \& Daly,M. (1993) Spousal Homicide Risk and Estrangements. Victims and Violence, 8, 3-16. 